\title{
Polyoma virus-associated carcinomas of the urologic tract: a clinicopathologic and molecular study
}

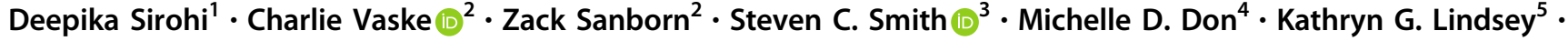 \\ Scot Federman ${ }^{1} \cdot$ Mahesha Vankalakunti $^{4} \cdot$ Jamie Koo $^{4}$. Shikha Bose ${ }^{4}$ Mariza de Peralta-Venturina ${ }^{4}$. \\ Jessica van Ziffle ${ }^{1}$. James P. Grenert ${ }^{1} \cdot$ Steve Miller $^{1} \cdot$ Charles Chiu $^{1} \cdot$ Mahul B. Amin $^{6} \cdot$ Jeffry P. Simko $^{1}$. \\ Bradley A. Stohr ${ }^{1} \cdot$ Daniel J. Luthringer ${ }^{4}$
}

Received: 28 January 2018 / Revised: 29 March 2018 / Accepted: 30 March 2018 / Published online: 15 May 2018

(c) United States \& Canadian Academy of Pathology 2018

\begin{abstract}
In recent years, there has been increased interest in carcinomas of the urologic tract, that demonstrate association with the polyoma virus BK arising in immunosuppressed individuals, though the nature of this association is uncertain. To begin to understand this phenomenon, we reviewed the clinical, morphological, and immunohistochemical features of 11 carcinomas of the urologic tract, mainly urothelial $(N=9)$ and collecting duct carcinomas $(N=2)$, occurring during immunosuppression, and expressing polyoma virus T-antigen by immunohistochemistry. These were compared to a control group of carcinomas $(N=8)$, also arising during immunosuppression, but without $\mathrm{T}$-antigen expression. A subset of both groups were also studied by hybrid capture-based DNA sequencing, probing not only for 479 cancer-related human genes, but also for polyoma and other viral sequences. Polyoma T-antigen-expressing tumors arose in 7 males and 4 females, at a median age of 66, and were aggressive, high-grade tumors with more than 1 variant morphologic pattern identified in $81 \%$ of cases, and a majority (73\%) presenting at high stage category (>pT3). Diffuse polyoma T-antigen staining was seen in $91 \%$ of cases, with co-localization of aberrant p53 staining in $89 \%$. Sequencing detected a lower number of deleterious mutations among T-antigen-expressing cases (average 1.62; 1/8 with TP53 mutation) compared to control cases (average 3.5, 2/4 with TP53 mutation). Only BK virus was detected with clonal integration and breakpoints randomly distributed across the human and viral genomes in $5 / 5$ of the polyoma $\mathrm{T}$-antigen-expressing carcinomas, and in none of the controls (0/4). In summary, these findings identify aggressive clinicopathologic features of polyoma T-antigen-expressing carcinomas, document BK as the strain involved, and associate BK viral integration with T-antigen expression and p53 aberrancy. While the apparent randomness of viral insertion sites is functionally unclear, the differing rates of mutations between $\mathrm{T}$-antigen-expressing and control cases is intriguing.
\end{abstract}

This work was presented in preliminary form at the 2017 United States and Canadian Academy of Pathology Meeting in San Antonio, TX and 2018 United States and Canadian Academy of Pathology Meeting in Vancouver, British Columbia, Canada.

Electronic supplementary material The online version of this article (https://doi.org/10.1038/s41379-018-0065-z) contains supplementary material, which is available to authorized users.

\footnotetext{
Deepika Sirohi

Deepika.Sirohi@hsc.utah.edu

1 Department of Pathology and Laboratory Medicine, University of California, San Francisco, CA, USA

2 NantOmics, Santa Cruz, CA, USA

3 Departments of Pathology and Urology, School of Medicine,
}

\section{Introduction}

Immunosuppressive therapy in the setting of solid organ transplants can be associated with adverse complications, especially opportunistic infections and malignancies. An overall 2-fold increased risk of cancers has been noted in large population-based studies of patients [1] following

Virginia Commonwealth University, Richmond, VA, USA

Department of Pathology and Laboratory Medicine, Cedars-Sinai Medical Center, Los Angeles, CA, USA

5 Medical University of South Carolina, Charleston, SC, USA

6 Department of Pathology and Laboratory Medicine and Urology, University of Tennessee Health Science, Memphis, TN, USA 
kidney, liver, heart, and lung transplantation. Many of these malignancies are due to the direct effect of oncogenic viruses. It is well known that in the immunocompromised setting, oncogenic viruses such as Epstein-Barr virus, human herpes virus 8 , human papilloma virus, Merkel cell polyoma virus, and hepatitis $\mathrm{B}$ and $\mathrm{C}$ viruses are associated with Hodgkin and non-Hodgkin lymphoma, Kaposi sarcoma and primary effusion lymphoma, anogenital cancer, Merkel cell carcinoma, and hepatocellular carcinoma, respectively. Understanding causative relationships between oncogenic viruses and specific malignancies can facilitate appropriate screening and foster the development of diagnostic and/or therapeutic tools, as are being currently implemented in some of these tumors such as those caused by hepatitis B and C viruses and human papilloma virus.

While the oncogenic roles of the above listed viruses are established, the functional nature of BK virus remains largely speculative. BK virus is a non-enveloped DNA virus that belongs to the Polyomaviridae family, members of which include progressive multifocal leukoencephalopathycausing JC virus, Simian virus 40 (SV-40) that causes subclinical infections, and Merkel cell carcinoma-inducing Merkel cell virus. BK virus is an established causative agent of nephropathy and allograft failure in renal transplant recipients. The virus has 6 genotypes based on DNA sequence variations; genotype 1 is the most common worldwide $(80 \%)$ [2, 3], followed by genotype IV $(15 \%)$. Reactivation of the virus can occur in immunocompromised hosts and in up to $30-50 \%$ of renal transplant recipients in the first 3 months after transplantation, irrespective of the type of immunosuppressive therapy. Viral shedding is seen in 16-35\% [2] of renal transplant recipients and up to $43 \%$ of those patients with high level BK virus infection $(>4 \log$ copies/mL) go on to develop BK virus allograft nephropathy with graft loss occurring in as many as $80 \%$. Other BK virus-associated urologic complications include ureteral stenosis which occurs in $2-10.3 \%$ of renal transplant recipients $[4,5]$ and hemorrhagic cystitis that can involve 6-29\% of bone marrow transplant recipients [6, 7]. BKVrelated neoplasms are relatively rare.

In recent years, increased attention has focused on ascertaining the role of BK virus in urologic malignancies arising in immunosuppressed post-transplant patients, especially renal transplants $[8,9]$. These tumors have generally been detected by immunohistochemistry techniques using antibodies raised against the large T-antigen of the polyoma virus SV-40, which also detects the T-antigen of $\mathrm{BK}$ and JC virus, and is used routinely to detect reactivation of BK virus seen in post-transplant kidney biopsies performed to evaluate allograft function. However, whether expression of this viral protein in carcinomas reflects an epiphenomenon of proximity of reactivated virus to genomically unstable carcinomas, or has a direct causative or contributory role in carcinogenesis, remains unclear $[9,10]$.

The reported malignancies in this setting have comprised a spectrum of high-grade urothelial carcinomas, collecting duct carcinomas, and renal cell carcinomas occurring up to several years post-transplant $[9,11,12]$. The tumors have occurred primarily in donor kidneys, and in one instance in a native kidney [13], and have demonstrated diffuse expression of the viral large $\mathrm{T}$ antigen by immunohistochemistry. In SV-40 transgenic mice, morphologically similar tumors are thought to arise through inactivation of $\mathrm{p} 53$ and $\mathrm{Rb}$ protein by the viral large T-antigen leading to uncontrolled cell proliferation $[14,15]$, although evidence of such a mechanism in human tumors is still lacking. The presence of the virus at high levels in the tumor, although suggestive, could imply either a true oncogenic role or passenger status in an actively proliferating tumor milieu. This is further confounded by the early acquisition of the viral infection during childhood with seroconversion in $\sim 50 \%$ of children by 3-4 years of age [16] and in $80 \%$ of adults [17], with persistence in a latent form in the urogenital tract even in healthy individuals. Viral integration into the nuclear genome of these tumors has been demonstrated in recent studies, resulting in disruption of the viral VP-1 gene and expression of $\mathrm{T}$-antigen, interpreted as supporting a pathogenic role for viral integration in oncogenesis in this subset of tumors $[9,10]$.

In this study, we describe the clinical and morphological spectrum of 11 polyoma virus T-antigen-expressing urologic carcinomas (urothelial and collecting duct carcinomas) with an aim of describing the morphologic features and outcomes, and with comparison to a cohort of non-expressing carcinomas also occurring in the setting of immunosuppression. Further, targeted sequencing of paired tumor and normal genome was performed in a subset of both groups of cases, with a goal to identify any molecular alterations that might define these tumors and to begin to assess the clinical and potential pathogenetic significance of BK virus in this unique cohort of urologic carcinomas.

\section{Materials and methods}

\section{Case selection}

A retrospective search of the electronic database of 4 tertiary centers including the consultation files of senior author (MBA) was performed to identify cases of polyoma $\mathrm{T}$-antigen-expressing urologic carcinomas arising in immunocompromised individuals. One of the cases has 
been previously reported [18]. Detailed evaluation of clinical charts was undertaken to identify underlying tumor risk factors, duration and cause of immunocompromised status, clinical presentation, associated infections and follow up. At one of the centers, Cedars Sinai Medical Center (CSMC), additional search was performed to identify polyoma $\mathrm{T}$-antigen non-expressing urologic carcinomas occurring during immunosuppression and record total number of solid organ and bone marrow transplants over the same time-period (January 2000 to December 2015). All available slides for cases were reviewed by two genitourinary pathologists (SCS and DS). This study was approved by respective Institutional Review Boards of each institution.

\section{Morphology and immunohistochemistry}

Tumor morphologies were evaluated for classification, variant patterns, necrosis, tumor giant cells, tumor stage and viral cytopathic changes in neoplastic and adjacent benign epithelium. Variant morphological patterns in the tumor greater than $5 \%$ were recorded. Immunohistochemistry for $\mathrm{p} 53$ and SV-40 polyoma virus large Tantigen (MRQ4 clone, Sigma- Aldrich, Inc., St Louis, MO) were performed in all cases following the manufacturer's protocols with appropriate positive and negative controls utilizing CLIA compliant protocols. Staining pattern of SV-40 and its relationship to p53 staining, if any, was assessed in neoplastic and benign epithelium. Staining for SV-40 was considered focal if there was immunoreactivity in $<10 \%$ of the lesional cells. Staining for p53 was considered aberrant when it was diffusely positive or completely absent and wild type when there was patchy staining.

\section{Targeted gene sequencing}

Targeted gene sequencing was performed on a subset of cases. For the test cohort of 8 polyoma T-antigenexpressing urologic carcinomas, matched normal and tumor tissues were selected for 7 tumors, and tumor only for 1 case (as normal tissue was not available) for sequencing. A control group comprised 4 post-transplant cases of polyoma $\mathrm{T}$-antigen non-expressing urothelial carcinomas (tumor and normal pair) that were negative for SV-40 by immunostaining. Capture-based next-generation sequencing was performed at the University of California, San Francisco Clinical Cancer Genomics Laboratory, using an assay (UCSF500 panel) that targets the coding regions of 479 cancer-related genes, select introns from approximately 40 genes, and the TERT promoter with a total sequencing footprint of $2.8 \mathrm{Mb}$ as previously described [19]. The assay also targets 10 polyoma viruses and 6 other viruses known to have association with cancers in humans. Viruses targeted on the panel include Hepatitis B, Human Herpes virus 4, Human immunodeficiency virus 1, Human papilloma virus 16, Human papilloma virus 18, Human Tlymphotropic virus type 1 , Merkel cell polyoma virus, BK polyoma virus, JC polyoma virus, KI polyoma virus, WU polyoma virus, Trichodysplasia-spinulosaassociated-polyoma virus, Human Polyoma virus 6, Human Polyoma virus 7, Human Polyoma virus 9, and MW-polyoma virus.

Variants were classified as pathogenic, likely pathogenic or variants of uncertain significance after filtering for population-based frequency greater than $1 \%$ and assessing frequencies in urologic cancers in c-Bioportal and COSMIC databases and pubmed search for prior established role as pathogenic.

\section{Viral detection, quantitation, and phylogenetic analysis}

Viral detection was done using the research version of the SURPI ("sequence-based ultra-rapid pathogen identification") computational pipeline for automated detection of pathogen sequences previously reported by some of the coauthors [20]. The March 2015 build of NCBI GenBank was used as the reference database for comparison. The preestablished criteria for viral pathogen identification was coverage of at least 2 non-contiguous/non-overlapping gene regions of size greater than the read length (140 bp). Viruses corresponding to non-pathogenic flora were not reported. Quantification of polyoma virus was done in both tumor and normal tissue by real-time polymerase chain reaction (PCR) for BKV using the Focus Diagnostic BKV assay containing a primer pair specific for the BK virus VP2 gene. The genome corresponding to the isolated $\mathrm{BK}$ virus was aligned together with selected $\mathrm{BK}$ virus genome sequences available in NCBI GenBank as of March 2017 using the MAFFT program in Geneious (Biomatters, Inc.) to identify the viral genotypes.

\section{Viral integration}

Viral integration analysis was performed by BamBam [21, 22] by two co-authors ( $\mathrm{CV}$ and $\mathrm{ZS}$ ). Sequence was aligned using bwa [23], marked for duplicates using superDeDuper [24], and GATK [25] was used for indel realignment and quality recalibration (see supplemental data for details). All viral integration sites were verified in Integrative Genomics Viewer (IGV). Nucleotide blast of sequence of reads unmapped to the human genome was performed to confirm viral sequences in the chimeric reads using the NCBI Basic Local Alignment Search Tool (BLAST). 


\section{Results}

\section{Clinicopathologic studies}

\section{Cohorts}

We identified 19 cases of carcinomas of the kidney and urinary bladder occurring in immunocompromised individuals, across 4 tertiary centers. Of these, 11 expressed polyoma virus $\mathrm{T}$-antigen by immunohistochemistry and were defined as polyoma $\mathrm{T}$-antigen-expressing urologic carcinomas, while 8 were negative, providing a control cohort of T-antigen non-expressing carcinomas, defining our test and control cohorts respectively.

Since the majority of the cases in our series were contributed from one institute (CSMC), we estimated the incidence of urologic malignancies and BK-associated malignancies in immunocompromised setting at this center. The total number of transplants over the same period (2000-2015) were 4087; with 2169 renal transplants, 975 liver transplants and 943 heart transplants. At this center, we identified 11 cases of urologic carcinomas occurring in individuals immunocompromised for various underlying causes. Of these, 10 cases were post-transplant, with 1 being status post bone marrow transplant and 9 status post solid organ transplants (renal and/or heart). None of the liver transplant patients at this center upon review of their records developed a subsequent urologic malignancy. The incidence of urologic carcinomas developing in individuals following renal and/ or heart transplant was 9/3112 (0.3\%) over 15 years. Of the 11 cases of urologic carcinomas occurring in immunocompromised setting, 5 were positive for T-antigen by immunohistochemistry (31\%), and of the 9 post solid organ transplant cohort, 4 were positive for T-antigen $(44 \%)$.

Five previously confirmed cases of T-antigen-expressing urologic carcinomas were submitted by collaborators, and one additional retrieved from consultation files of one of the authors (MBA), all of which were status post renal transplant. Additionally, one case was previously encountered on clinical service at CSMC in a patient who had a history of colorectal adenocarcinoma and bullous pemphigoid treated by prolonged immunosuppressive steroid therapy (previously reported) [18], resulting in a cohort of 11 cases of Tantigen-expressing carcinomas. Paraffin blocks were available for 8 of these cases for sequencing studies.

\section{Clinical features}

The 11 cases of $\mathrm{T}$-antigen-expressing carcinomas in immunocompromised individuals occurred at a mean age of 60 years (range 37-80, median 66), and showed a slightly higher predilection for males with a male: female ratio of
1.75:1 (Table 1). Risk factors for development of conventional type urologic neoplasms were identified in 2 cases; one with a long history of smoking and another being a painter by occupation. The mean time of detection of malignancy post immunosuppression was 7 years (range 1-11). BK viremia antedated the tumor in 5 cases averaging 5.6 years (range $2-10)$. BK viral loads were not monitored in other cases. The cause of immunosuppressed status included solid organ transplants: combined heart and renal $(N=3)$, heart only $(N$ $=1)$, renal only $(N=6)$; and 1 case was on prolonged immunosuppressive steroid therapy. Eight of eleven (73\%) cases were high stage (pT3 or greater), pT2a for 1, pT1 for 1 , which was incidentally detected at autopsy, and 1 nontransplant case presented with in situ disease (pTiS). Follow up was available for 10 patients over a mean of 24 months (range 1-132, median 12). One patient died of metastatic disease, two died of unrelated causes, three had recurrent/ metastatic disease, and four were alive with no recurrences.

In comparison, the 8 polyoma T-antigen non-expressing carcinomas showed a similar age and sex distribution occurring at a mean age of 66.6 years (range 48-87, median 68 ); with a male: female ratio of 1.7. The mean duration of immunosuppression before onset of carcinoma was longer at 8.6 years (range $0.16-26$ ). These tumors occurred following renal transplant in 3 cases, heart transplant in 2 , bone marrow transplant in 1 , and following radiotherapy in 1 . These cases were distributed across stages pTis $(n=1)$, pTa $(n=2)$, pT1 $(n=3)$, pT2a $(n=2)$ with no pT3 or higher stage tumors. Follow up was available over a mean duration of 17.9 months (range 1-48, median 12) with no recurrence in 2 cases, alive with local disease recurrence in 5 and death due to metastatic disease in 1 . While the other parameters were not statistically different between the two cohorts, the stage distribution was statistically significant with $73 \%$ of cases being $\mathrm{T} 3$ or higher stage in the $\mathrm{T}$ antigen-expressing carcinomas and none of the cases in the T-antigen non-expressing carcinomas $(p=0.0034)$.

\section{Microscopic features}

In the polyoma $\mathrm{T}$-antigen-expressing group, tumors were found in the bladder $(N=8)$, ureter $(N=1)$ and renal pelvis $(N=2)$ and were classified as urothelial carcinoma $(N=9)$ and collecting duct carcinoma $(N=2)$ (Table 1). All urothelial carcinomas showed variable degrees of variant morphologic patterns (including glandular-not otherwise specified, villoglandular, enteric, plasmacytoid, micropapillary, signet ring) with more than one pattern present in 9 of $11(81 \%)$ cases (Table 2, Fig. 1). Sarcomatoid differentiation was identified in 3 cases, tumor necrosis in 4 , and tumor giant cells in 3 . Except for 1 case with focal staining in $10 \%$ cells, the cases showed strong and diffuse SV-40 immunoreactivity in more than $90 \%$ of the lesional cells. 





Table 2 Morphologic and immunohistochemical features of the polyoma T-antigen-expressing carcinomas

\begin{tabular}{|c|c|c|c|c|}
\hline Case \# & Pathology & Aggressive histologic features & p53 lesion & $\begin{array}{l}\text { SV-40 background } \\
\text { epithelium }\end{array}$ \\
\hline 1 & HGUC & Sarcomatoid, signet ring cell, necrosis & Aberrant (diffusely + ) & - \\
\hline 2 & HGUC & Villoglandular, micropapillary, signet ring cell & Aberrant (diffusely + ) & - \\
\hline 3 & $\mathrm{CDC}$ & $\mathrm{CDC}$ & Aberrant (diffusely + ) & - \\
\hline 4 & $\mathrm{CDC}$ & $\mathrm{CDC}$ & Not done & + , focal \\
\hline 5 & HGUC & Glandular-NOS & Not done & - \\
\hline 6 & $\begin{array}{l}\text { HGUC upper renal } \\
\text { calyx }\end{array}$ & $\begin{array}{l}\text { Sarcomatoid, glandular-NOS, papillary non-invasive, } \\
\text { micropapillary, solid }\end{array}$ & Aberrant (diffusely + ) &,+ focal \\
\hline 7 & HGUC & Glandular-NOS, necrosis & Aberrant (diffusely + ) & - \\
\hline 8 & HGUC & $\begin{array}{l}\text { Glandular-NOS, micropapillary, sarcomatoid, tumor } \\
\text { giant cells, necrosis }\end{array}$ & $\begin{array}{l}\text { Aberrant (completely } \\
\text { negative) }\end{array}$ & - \\
\hline 9 & HGUC & Glandular-NOS, tumor giant cells, mucin, necrosis & Aberrant (diffusely + ) & - \\
\hline 10 & HGUC & Glandular-NOS & WT & - \\
\hline 11 & HGUC & $\begin{array}{l}\text { Glandular-NOS, enteric, micropapillary. bizarre giant } \\
\text { cells, mucin }\end{array}$ & Aberrant (diffusely + ) & N/A \\
\hline
\end{tabular}

CDC Collecting duct carcinoma, HGPUC high-grade papillary urothelial carcinoma, HGUC high-grade urothelial carcinoma, N/A not available, $W T$ wild type, NOS not otherwise specified

p53 expression was diffusely aberrant in 8 of 9 cases studied (Fig. 1) and wild-type expression was seen in 1 case. Background non-neoplastic epithelium was focally positive for SV-40 in 2 of 10 cases. Importantly, in the polyoma Tantigen non-expressing cohort, 4 of 5 cases tested showed diffuse aberrant expression of p53 (diffusely positive in 3 and completely absent in 1) while 1 showed a wild-type staining pattern. In the T-antigen non-expressing group all cases were identified in the bladder. The spectrum of neoplastic lesions in this group included 6 high-grade urothelial carcinomas, 1 low grade papillary urothelial carcinoma and 1 urothelial carcinoma in situ. The urothelial carcinomas were conventional high-grade urothelial carcinomas with variant morphology seen in 1 of 6 cases, which was significantly less than the variant morphologic patterns seen in the T-antigen-expressing group ( $p=0.035)$.

\section{Molecular analyses}

Targeted next-generation sequencing data was used to identify missense variants, insertions, deletions, structural rearrangements, and copy number changes. These studies were completed in 8 polyoma T-antigen-expressing carcinomas and 4 non-expressing cases. TERT promoter mutations were the most frequent pathogenic alteration in the polyoma $\mathrm{T}$ antigen-expressing group ( 4 of 8 cases, $50 \%$ ) as compared to $100 \%$ in the 4 non-expressing controls (Table 3 ). The average number of pathogenic or likely pathogenic mutations was 1.62 (range 0-5) in the T-antigen-expressing cohort and 3.5 in the non-expressing cohort (range $1-7),(p=0.17)$. For reference, the average number of pathogenic/likely pathogenic mutations in urothelial carcinomas occurring in non- immunosuppressed individuals in our internal database of 18 (unselected for immunocompromised setting) urothelial carcinomas tested using the same molecular platform is 6.82 (range 3-10, data not shown). The differences were not statistically significant across the groups. A TP53 inactivating mutation was seen in 1 of 8 cases in the T-antigenexpressing carcinomas, 2 of 4 in the non-expressing cohort, and in 10 of 18 cases in the non-immunosuppressed cohort (internal database). The TP53 mutation positive case (case 8) showed complete lack of staining with $\mathrm{p} 53$ and had focal SV40 staining of the lesional cells.

Importantly, given that polyoma immunohistochemistry might detect viral $\mathrm{T}$-antigen from several closely related polyoma viruses, sequencing studies detected BK virus, in both normal and tumor samples of all T-antigen-expressing carcinomas (including one with only focal expression) and from none of the T-antigen non-expressing tumors. No other viruses were detected in any cases. Phylogenetic analysis assigned the BK virus genotypes to genotype $\mathrm{VI}$ in 5 cases, $1 \mathrm{a}$ in 2 , and IV in 1 (Table 4).

Since the virus was detected in both tumor and normal samples of polyoma T-antigen-expressing cases, a quantitative PCR for BK virus was done in 4 paired normal and tumor samples. In 4 cases, viral detection could not be performed due to technical limitations. The mean viral load was $12,439,554$ copies/mL in tumor samples and 426,039 copies/mL in normal samples.

Next, the viral sequences were analyzed for chimeric human and viral reads, indicative of viral integration in the human genome. In 3 cases, the ratio of viral reads to human reads in normal and tumor was too low to detect any chimeric reads. In 5 cases, an average of 3 (range 1 to 6 ) clonal 




Fig. $1 \mathrm{BKV}$-associated urologic malignancies: morphologic spectrum. a-e Variant morphologies seen in these tumors include: a Sarcomatoid pattern, (h\&e, $\times 4)$; b enteric pattern, ( $h \& \mathrm{e}, \times 10)$; c micropapillary pattern, (h\&e, $\times 10)$; d signet ring cell features, $(\mathrm{h} \& \mathrm{e}, \times 10)$; e mucinous

chimeric viral and human reads were identified in the tumor samples that were not detected in the normal samples. Each of the chimeric reads was visualized in IGV (Fig. 2) and nucleotide blast performed on the sequences of unmapped reads that mapped to BK viral genome, confirming viral integration in the human genome. Additionally, an average of 7 (range 1-13) internal structural rearrangements were identified within the viral genomes.

The breakpoints in the human genome included exonic, intronic and intergenic regions (Table 5). The breakpoints occurred in 6 different genes, TSTD1, CHKA, MUC6, MACROD2, CAPN1, and SCAPER. The chimeric reads on mapping to the reference BK viral genome (NC_001538.1) demonstrated breakpoints distributed across the viral genome, including within VP-1, VP-2, VP-3, and small and large Tantigens (Figs. 3 and 4). The number of viral reads in the chimeric fusions ranged from as low as 4 to 402 reads. The integration sites were clonal but not site specific and were randomly distributed across both the viral and the human genome. Though no integration sites were identified in normal tissue, the possibility of low-level integration below the limit of sequencing detection cannot be entirely excluded.

\section{Discussion}

The study cohort, though small, expands rare observations about BK virus-associated tumors, extends prior clinical pattern, (h\&e, $\times 4$ ); $\mathbf{f}-\mathbf{i}$ immunohistochemical findings; $\mathbf{f}$ diffuse SV-40 positivity is seen in tumor cells. $\mathbf{g}$ In contrast the adjacent benign urothelium is negative for SV-40. h, i SV-40 (h) and p53 (i) immunohistochemistry stains showing diffuse positivity and co-localization

and molecular observations $[9,10]$ and compares the Tantigen-expressing carcinomas to a relevant control group of T-antigen non-expressing but immunosuppressionassociated carcinomas. Moreover, our use of capturebased high-throughput sequencing, including of viral sequences, yields key, complimentary molecular findings, confirming the specificity of $\mathrm{T}$-antigen expression to $\mathrm{BK}$ viral integration into the genome of these tumors, and beginning to shed light on important questions regarding the relationship of BK to tumorigenesis.

Immunohistochemistry for SV-40 T-antigen was employed to define the T-antigen-expressing and nonexpressing carcinomas that were the test and control cohorts, respectively. The immunohistochemical stain (MRQ4 clone, Sigma- Aldrich, Inc., St Louis, MO) is directed at the polyoma virus large T-antigen and detects the T-antigen of the BK and JC virus. For the former reason, it is employed in routine clinical practice to detect BK virusassociated nephropathy. Similar antibody clones have been used in most reported studies to diagnose BK virusassociated carcinomas. In evaluating the efficacy of the SV40 immunohistochemical stain by comparing with viral detection and integration data, all $\mathrm{T}$-antigen-expressing carcinomas that were tested demonstrated BK virus, and viral integration in a subset, while none of the T-antigen non-expressing carcinomas showed BK or any other viral integration, despite the high prevalence of BK viral reactivation in post-transplant patients. Moreover, no other 
Table 3 Pathogenic and likely pathogenic mutations in the polyoma $\mathrm{T}$-antigen-expressing and non-expressing carcinomas

\begin{tabular}{|c|c|c|c|}
\hline \multicolumn{2}{|c|}{$\begin{array}{l}\text { Polyoma T-antigen-expressing } \\
\text { carcinomas }\end{array}$} & \multicolumn{2}{|c|}{$\begin{array}{l}\text { Polyoma T-antigen non- } \\
\text { expressing carcinomas }\end{array}$} \\
\hline Case \# & $\begin{array}{l}\text { Pathogenic/likely } \\
\text { pathogenic variants }\end{array}$ & Case \# & $\begin{array}{l}\text { Pathogenic/likely } \\
\text { pathogenic variants }\end{array}$ \\
\hline 1 & PIK3R1 c. $1299+2 \mathrm{~T}>\mathrm{A}$ & 13 & $\begin{array}{l}\text { MYC amplification } \\
K R A S \text { p.G12D } \\
T E R T \text { promoter mutation } \\
(-124 \mathrm{C}>\mathrm{T}) \\
I G F 2 R \text { c. } 6068+1 \mathrm{G}>\mathrm{A} \\
T P 53 \text { structural variant } \\
\text { (intron } 1)\end{array}$ \\
\hline 2 & None & 14 & $\begin{array}{l}F G F R 3 \text { p.Y373C } \\
A R I D 1 A \text { p.G1178fs } \\
K D M 6 A \mathrm{p} .5637 \mathrm{fs} \\
T S C 1 \text { p.E31fs } \\
K M T 2 D \text { c. } 16339-2 \mathrm{~A}>\mathrm{G} \\
K M T 2 D \text { p. } 2708 \mathrm{fs} \\
T E R T \text { promoter } \\
\text { c. }-146 \mathrm{C}>\mathrm{T}\end{array}$ \\
\hline 3 & $\begin{array}{l}\text { TERT promoter } \\
\text { c. }-124 \mathrm{C}>\mathrm{T} \\
\text { KDM6A p.E } 1102 \mathrm{~K}\end{array}$ & 15 & $\begin{array}{l}\text { TERT promoter } \\
\text { c. }-124 \mathrm{C}>\mathrm{T}\end{array}$ \\
\hline 6 & None & 16 & $\begin{array}{l}\text { TERT promoter } \\
\text { c. }-124 \mathrm{C}>\mathrm{T} \\
\text { TP53 p.E285* } \\
\text { KDM6A p.E153* } \\
\text { RB1 p.V654fs } \\
\text { DUSP4 p.V2fs } \\
\text { ARID1A p.W337* }\end{array}$ \\
\hline 7 & $\begin{array}{l}\text { TERT promoter } \\
\text { c. }-124 \mathrm{C}>\mathrm{T}\end{array}$ & & \\
\hline 8 & $\begin{array}{l}P I K 3 C A \text { p.Q546K } \\
\text { TP53 p.R213* } \\
\text { RB1 p.S780* } \\
\text { KMT2D p.P2499fs } \\
\text { NCOR1 p.R190* }\end{array}$ & & \\
\hline 9 & $\begin{array}{l}\text { TERT promoter } \\
\text { c. }-124 \mathrm{C}>\mathrm{T} \\
\text { KDM6A p.G156 }\end{array}$ & & \\
\hline 11 & $\begin{array}{l}\text { TERT promoter } \\
\text { c. }-124 \mathrm{C}>\mathrm{T} \\
E R B B 3 \text { p.Q788* }\end{array}$ & & \\
\hline
\end{tabular}

viruses or known pathogens were identified in the Tantigen-expressing or the non-expressing groups. These findings validate the specificity of the SV-40 polyoma virus large $\mathrm{T}$-antigen immunohistochemistry assay for $\mathrm{BK}$ viral large $\mathrm{T}$-antigen when used in the right clinical context. They also further support the specificity of the association of BK virus carcinoma in prior reports of urologic carcinomas in post-transplant patients established on basis of immunohistochemical assays.

Although the incidence of urothelial carcinomas in the current study in post heart and/or renal transplant $(0.02 \%)$ was not different from that in the general non-transplant
Table 4 BK viral detection across tumor and normal samples

\begin{tabular}{llllll}
\hline Case \# $\begin{array}{l}\text { Sample } \\
\text { designation }\end{array}$ & $\begin{array}{l}\text { \# of BKV } \\
\text { reads }\end{array}$ & $\begin{array}{l}\text { BK viral } \\
\text { detection } \\
\text { by “Surpi”" }\end{array}$ & $\begin{array}{l}\text { BKV } \\
\text { viral } \\
\text { load-PCR } \\
\text { copies/mL }\end{array}$ & $\begin{array}{l}\text { Viral } \\
\text { genotype }\end{array}$ \\
\hline 1 & Normal & 187 & + & 17,572 & $1 \mathrm{a}$ \\
& Tumor & 41,634 & + & $57,453,631$ & \\
2 & Normal & 2575 & + & 92,426 & VI \\
& Tumor & 4382 & + & 486,885 & \\
3 & Normal & 3393 & + & 430,508 & VI \\
& Tumor & 49,849 & + & $4,153,309$ & \\
6 & Normal & 2482 & + & $1,163,650$ & $1 \mathrm{a}$ \\
& Tumor & 436,762 & + & 103,679 & \\
7 & Normal & 1167 & + & ND & VI \\
& Tumor & $1,218,735$ & + & ND & \\
8 & Normal & 76 & + & ND & VI \\
& Tumor & 16 & + & ND & \\
9 & Normal & 2453 & + & Not done & VI \\
& Tumor & 8675 & + & Not done & \\
11 & Tumor & 6675 & + & 266.379 & IV \\
\hline
\end{tabular}

population in US (19.8 per 100,000 per year), what draws attention is that almost half of these were associated with $\mathrm{BK}$ virus-expressing polyoma T-antigen [26]. Similar to earlier reports, the morphologic spectrum of polyoma T-antigenexpressing urologic carcinomas in this study was varied and included both primary urothelial carcinomas of the urinary bladder and upper urothelial tract as well as carcinomas with collecting duct pattern, arising in the renal collecting system. The clinical features for both the T-antigen-expressing and non-expressing carcinomas cohorts in this study were similarly distributed with respect to age, sex and types of transplants/ immunosuppressed states. However, the vast majority $(73 \%)$ of carcinomas occurring in the T-antigenexpressing group presented with pT3 or higher stage disease in contrast to $0 \%$ in the negative cohort $(p=0.0034)$. These findings are consistent with prior reports of high-grade urothelial carcinomas with conventional and/or variant morphologies and collecting duct carcinomas occurring in transplant recipients that show polyoma virus $\mathrm{T}$-antigen expression but lack evidence of viral replication [8, 9]. The variant morphologies seen, generally deemed in urothelial carcinoma to be reflective of aggressive tumor biology included glandular, villoglandular, enteric, plasmacytoid, micropapillary, signet ring, and sarcomatoid differentiation, also consistent with prior case reports and series [9, 12, 27]. In particular, more than one variant morphology was seen in $81 \%$ of the T-antigen-expressing cases, in contrast to $17 \%$ in the T-antigen non-expressing group. The high-grade tumors, presence of more than one variant pattern and tumor giant cells were important findings not routinely encountered in urothelial carcinomas that might serve as clues prompting 


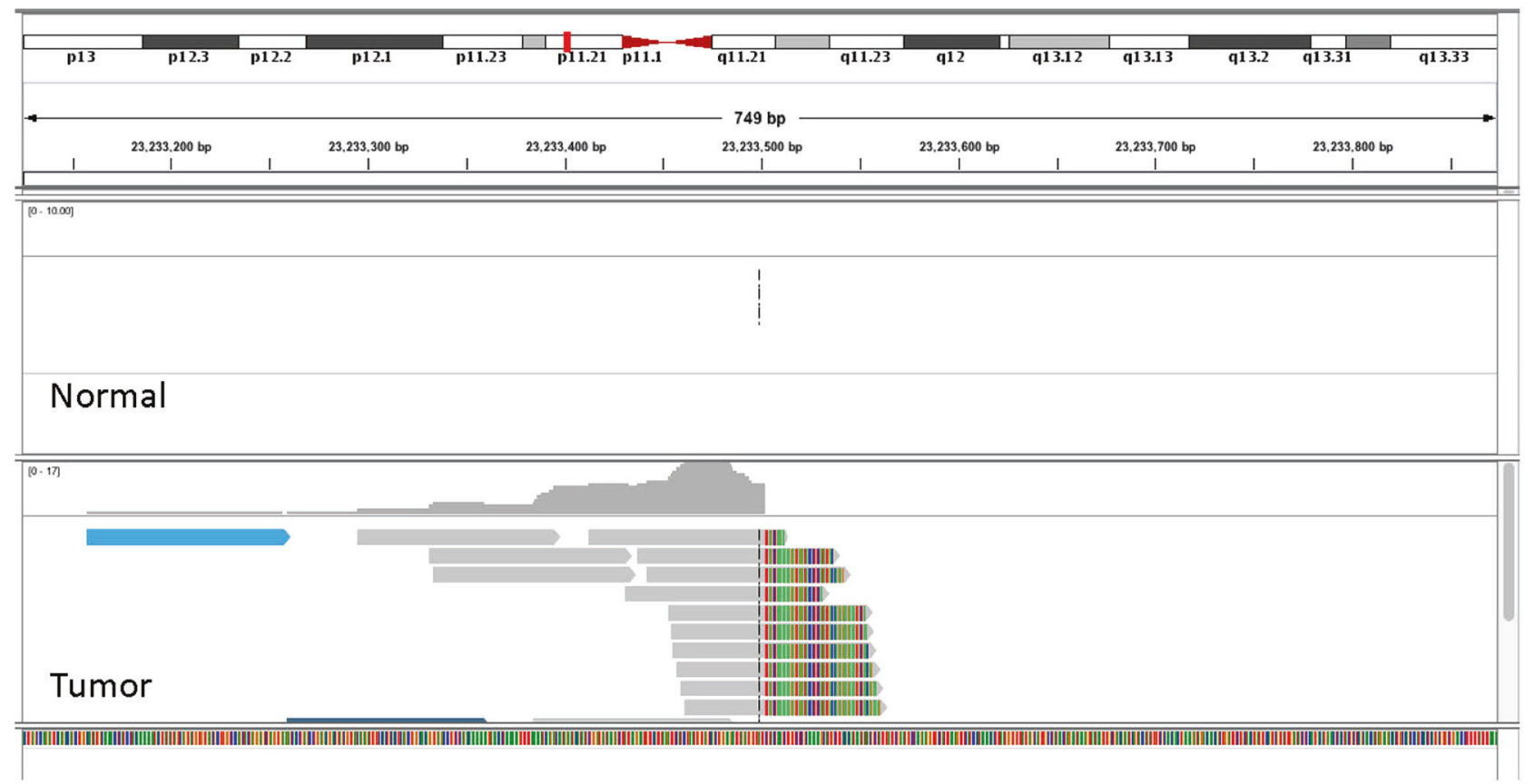

Fig. 2 BK viral integration sites visualized in Integrated Genome Viewer. The top panel represents the normal and the lower tumor. A chimeric fusion is identified in the tumor with breakpoint in intron 9 of

evaluation for viral studies in an appropriate clinical setting. The similar demographics of the T-antigen-expressing and non-expressing groups is reflective of the clinical profile of individuals undergoing organ transplants. On the other hand, the high stage and aggressive disease morphology in the Tantigen-expressing group is likely related to the underlying immunosuppressed state further exacerbated by secondary BK viral infection.

The T-antigen of BK virus is thought to function by binding to tumor suppressors of the $\mathrm{Rb}$ family including p53. As in many earlier case reports, immunohistochemical expression of $\mathrm{p} 53$ closely paralleled that of SV-40. Aberrant diffuse expression of p53 was seen in all cases, except one that showed complete lack of staining and a corroborative inactivating TP53 mutation. Viral integration was not feasible in this case because of low level of viral reads in both the tumor and normal sample. It is possible that this case with focal SV-40 positivity and inactivating TP53 mutation was not truly a polyoma T-antigen-expressing carcinoma, but instead had incidental viral co-infection of the tumor. Additionally, aberrant p53 expression was also seen in the 4 of 5 negative controls, both with and without TP53 gene alterations. TP53 and $R b$ gene alterations were rare in the $\mathrm{T}$-antigen-expressing and non-expressing groups present in $1 / 8$ and $2 / 4$ cases respectively, while present in more than half of the non-transplant carcinomas (10/18). The lack of $T P 53$ and $R b$ gene alterations and aberrant diffuse expression of p53 protein in both the polyoma T-antigenexpressing and non-expressing cohort suggests alternate
MACROD2 gene on chr 20. The fusion maps across half the reads to the human genome (gray) and the other half (colored) is unmapped. Blast of the unmapped sequences align to the BKV genome

Table 5 BK viral integration sites in human and viral genome

\begin{tabular}{|c|c|c|}
\hline Case \# & $\begin{array}{l}\text { Integration sites in } \\
\text { human genome }\end{array}$ & $\begin{array}{l}\text { Integration sites in } \\
\text { viral genome }\end{array}$ \\
\hline 1 & $\begin{array}{l}\text { TSTD1: exon2 } \\
\text { Intergenic } U N C 5 D / \\
D U S P 26\end{array}$ & $\begin{array}{l}\text { VP-2/3 } \\
\text { VP-1 }\end{array}$ \\
\hline 3 & $\begin{array}{l}\text { Intergenic } C 1 Q T N F 7 / \\
C P E B 2\end{array}$ & Large $\mathrm{T}$ - antigen \\
\hline 6 & $\begin{array}{l}C H K A \text { : intron } 4 \\
C H K A \text { : intron } 5 \\
C H K A \text { : intron } 6 \\
M A C R O D 2: \text { intron } 9 \\
C A P N 1 \text { : exon } 10 / 11 \\
\text { Intergenic } N X T 1 / C D 93\end{array}$ & $\begin{array}{l}\text { Large T- antigen } \\
\text { Large T- antigen } \\
\text { Small T- antigen } \\
\text { Small T- antigen } \\
\text { Large T- antigen } \\
\text { Large T- antigen }\end{array}$ \\
\hline 7 & $\begin{array}{l}\text { SCAPER: intron } 23 \\
\text { SCAPER: intron } 15 \\
\text { Intergenic ZNF703/ } \\
\text { KCNU1 } \\
\text { Intergenic } \\
C C C D C 144 N L / \\
C D R T 15 L 2 \\
\text { Intergenic RPE65/WLS }\end{array}$ & $\begin{array}{l}\text { Small T-antigen } \\
\text { Large T-antigen } \\
\text { Large T-antigen } \\
\text { NCCR } \\
\text { NCCR }\end{array}$ \\
\hline 11 & MUC6: intron 24 & VP-2/3 \\
\hline
\end{tabular}

mechanisms of gene inactivation and/or protein sequestration. The paucity of alterations in these 2 key genes of the cell cycle regulatory pathway would be biologically relevant, given that $\mathrm{T}$-antigen disrupts their functioning. In light of the morphologic overlap of collecting duct carcinomas and fumarate hydratase $(\mathrm{FH})$-deficient renal cell carcinomas $[28,29]$, it is also worth noting that the collecting duct 


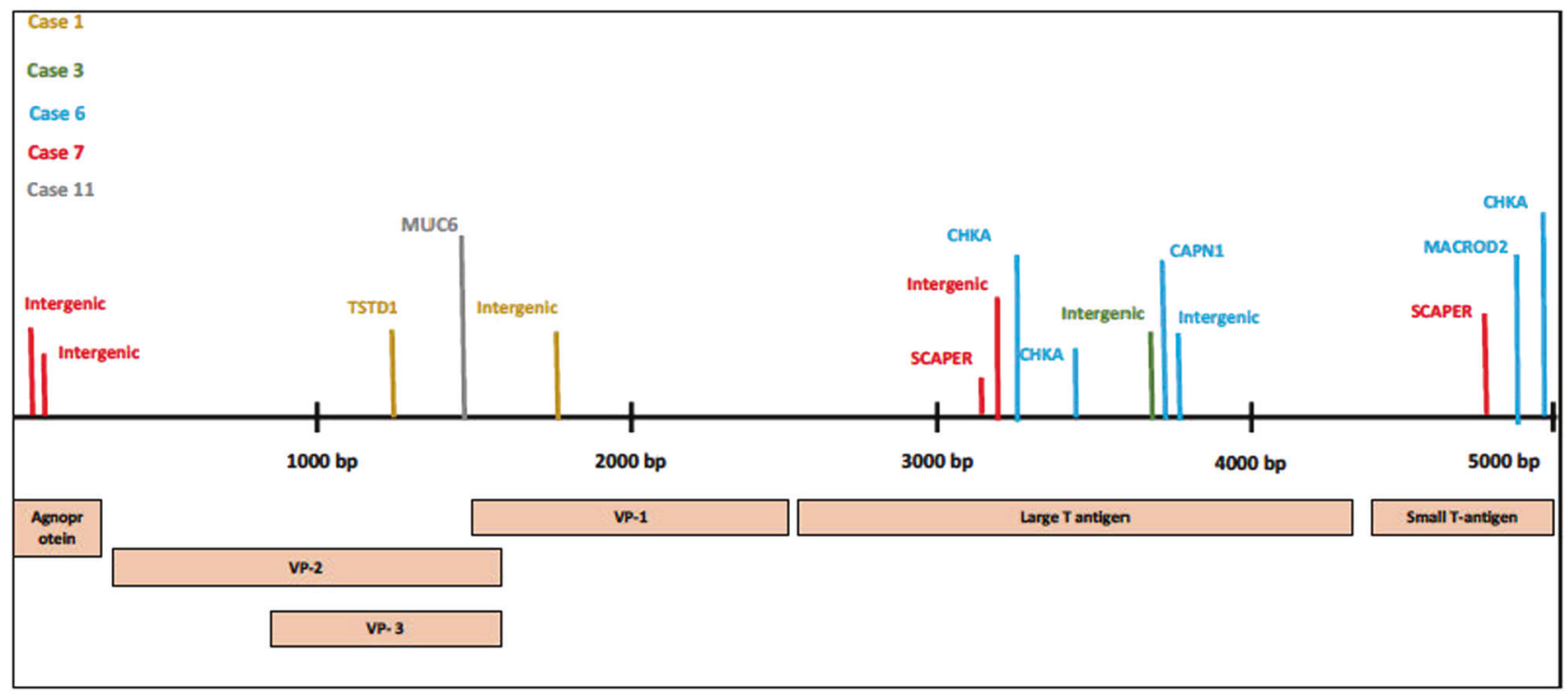

Fig. 3 BK viral integration sites. Breakpoints across viral genomic regions and corresponding sites in human genome are depicted. The breakpoints are distributed across all key regions and multiple integration sites are seen in most cases

carcinoma case that was sequenced did not show any alterations of the $F H$ gene.

Interestingly, although the spectrum of molecular alterations across the two test groups were similar and consistent with those seen in urothelial carcinomas, the average number of pathogenic mutations in the T-antigenexpressing carcinomas was less than those seen in the T-antigen non-expressing carcinomas and conventional urothelial carcinomas occurring in non-immunosuppressed individuals. This difference, although not statistically significant in this small cohort is intriguing and raises the possibility of alternate molecular pathways to oncogenesis in these tumors.

Further viral detection and integration demonstrated that in contrast to the serologic prevalence of the most common genotypes I and IV $[2,3]$ and prior report of genotypes $1 \mathrm{~b}$ $[10,12,27]$ and IV [12] in urothelial carcinomas; genotype VI $(5 / 8$ cases $)$ was the most prevalent in this cohort of polyoma T-antigen-expressing carcinomas. The small size of the study cohort precludes interpretation of significance of this skewed genotype prevalence or, ascertainment whether specific BK virus genotypes might be more oncogenic warranting additional prospective studies.

On evaluating the integration sites in our study, breakpoints of viral integration involved exonic, intronic and intergenic sites in the human genome. The exonic and intronic viral integration created fusions with 6 different human genes: TSTD1, CHKA, MUC6, MACROD2, CAPN1, and SCAPER, 5 of which have been implicated in cancers [30-35]. SCAPER is a Cyclin A substrate that forms a complex with it to regulate its kinase activity and may have a role in G1/S and G2/M phases of cell cycle [36]. No recurrent breakpoint hotspots were identified in these specimens warranting prospective analysis of additional cases. The viral integration site in these cases was random in both the viral and human genome, and in some cases, multiple exonic, intronic, and intergenic integration sites were identified. The clonal integration sites were detected in the tumor samples but not in normal samples, suggesting clonal expansion of cells with viral integration. The significance of intergenic fusions is uncertain at this time. Similarly, in the viral genome the integration sites were random, involving almost every key genomic region of the virus.

Viral integration in the tumor genome with disruption of the lytic cycle is a key feature of viral oncogenesis [37]. The circular double stranded DNA genome of BK virus has 3 main regions: an early region transcribed prior to DNA replication, a late region transcribed after DNA replication and a non-coding control region with transcription factors for early and late genes. The genes encoded by the early region include the large (T-antigen) and the small (t-antigen) tumor antigen and the late region encodes for the viral capsid proteins VP1, VP2, VP3, and agnoprotein [38]. The polyoma viral life cycle is regulated by coordinated transcription of both the early T-antigen and late VP regions of the viral genome enabling a lytic life cycle. With the uncoupling of the early and the late region, the lytic life cycle is disrupted allowing continued survival of the virus within non-permissive host cells, promoting oncogenesis [12]. Like many oncogenic viruses, inactivation of cell cycle regulators such as TP53 and RBI by large and small $\mathrm{T}$-antigen is thought to drive oncogenesis.

Data for integration sites of other known oncogenic viruses have shown that integration sites have varied from 


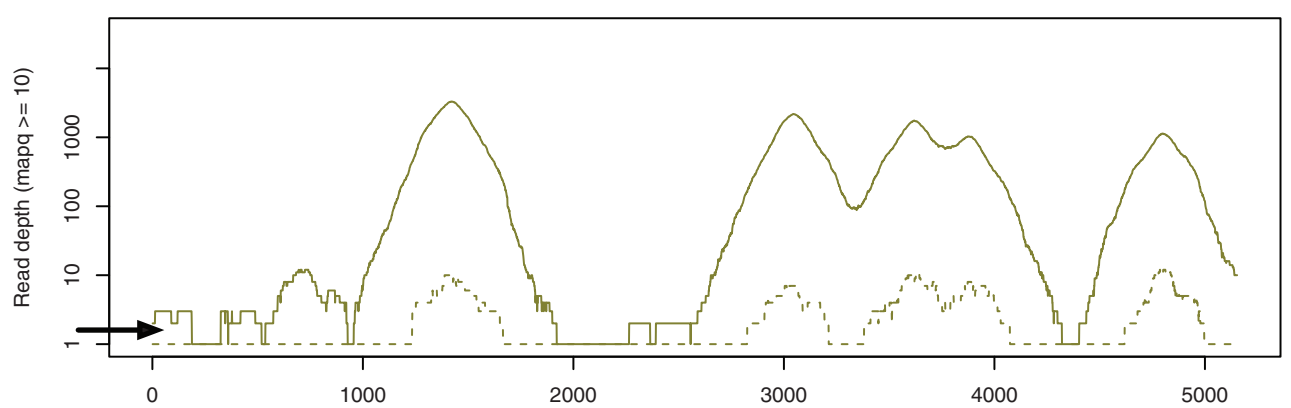

Case 1

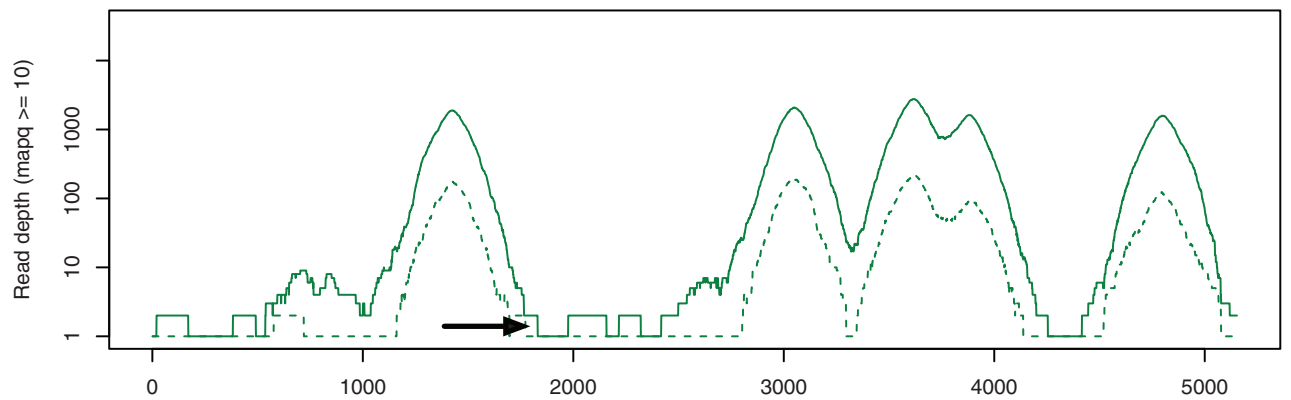

Case 3

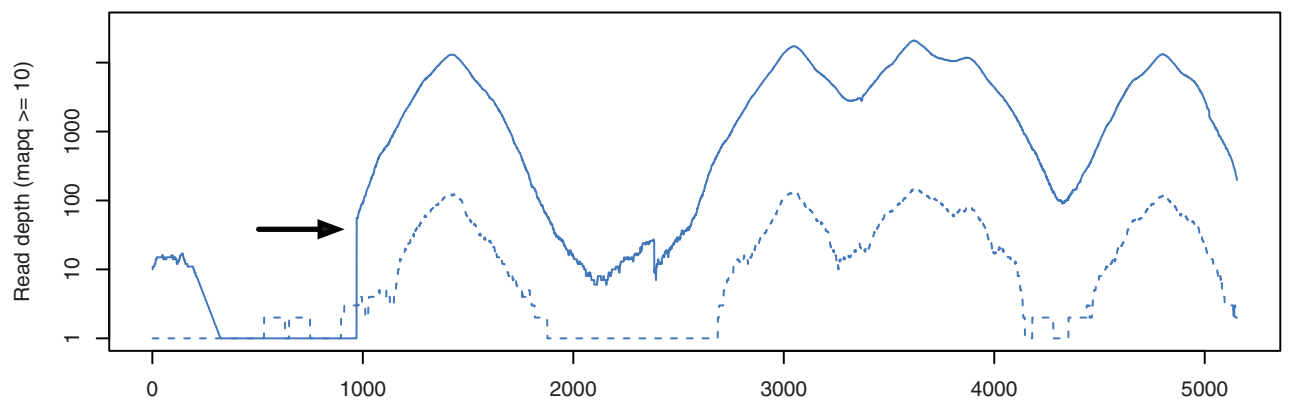

Case 6

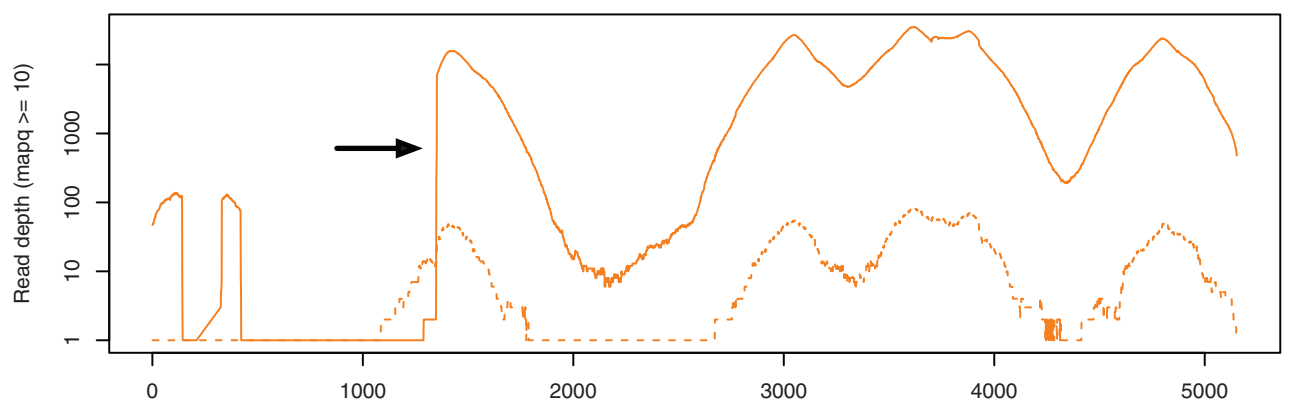

Case 7

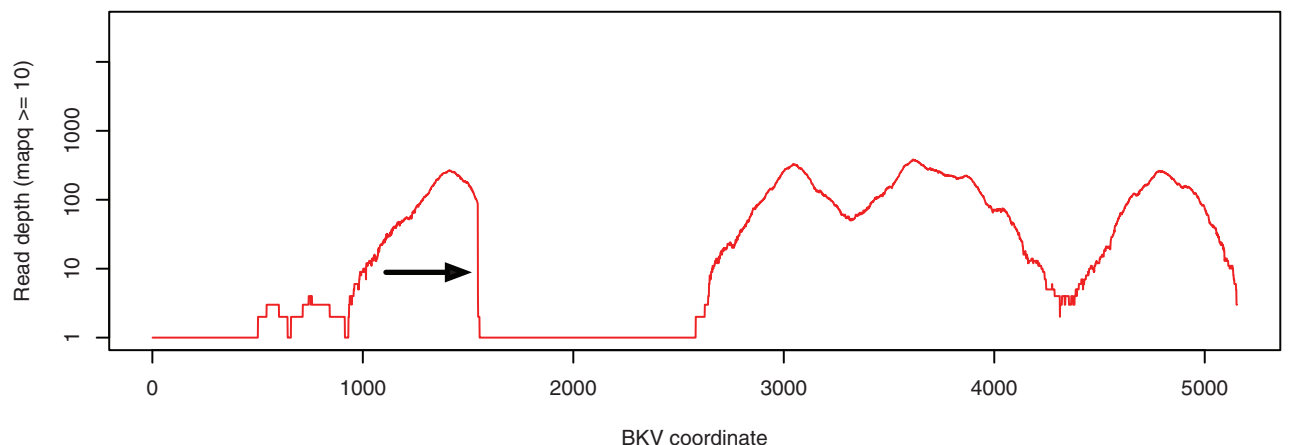

Case 11

Fig. 4 Coverage plots of viral reads across BK viral genome are depicted. The sharp drop offs are the sites of breakpoints in the viral genome that are more readily visualized at this magnification for integration sites with greater read depths (representative highlighted with arrows) 
recurrent hotspots to random integration $[39,40]$. In the context of BK virus-associated urologic malignancies, viral integration sites have been investigated by 2 studies in renal and bladder cancers. Kenan et al. analyzed two cases of renal and UC. They identified a fusion with breakpoint involving the VP-1 region of the viral $\mathrm{CH}-1$ isolate and exon 26 of human $M Y B P C 1$ gene and resultant linearization of the viral genome in UC. While genes encoding for the large and small T-antigens were intact, there was deletion of the $\mathrm{Q}$ and $\mathrm{R}$ sequencing blocks of the NCCR gene. In the renal carcinoma, the breakpoint involved intron 5 of the BRE human gene and VP-1 region of the BK virus. They hypothesized host cell survival and neoplastic transformation consequent to T-antigen expression with loss of late gene replication $[9,10]$. The second study identified two integration sites in one of their 2 cases analyzed [27]. The integration sites were located between the $\mathrm{C}$-terminal end of the BKV VP1 gene and the human DPY19L2 gene on chromosome 12 (intron 18). The second integration site was the human $R A B 8 B$ (intron 1) gene on chromosome 15, and the large T-antigen side of the NCCR of the viral genome. Viral particles were not identified on electron microscopy in the tumor cells [27]. Another study looking at urothelial carcinomas identified BK viral integration using nested PCR in two cases, and again viral particles were not identified in the tumor cells on electron microscopy [12].

While in our study the breakpoints in the viral and human genome created by viral integration occurred randomly, nevertheless these would result in uncoupling of the early and late viral genes and be disruptive to a lytic viral cycle. Although the binding and inactivation of cell cycle regulatory proteins $\mathrm{p} 53$ and $\mathrm{pRb}$ to the $\mathrm{T}$-antigen have been previously established [41], the disruption of T-antigen in 3 of 5 cases would be inconsistent with such a mechanism, as would be the functional effect of random insertions seen in these 5 cases and prior reports. Random tumor integration is a well-established phenomenon in many of the known oncogenic viruses, but these typically involve interruption of known viral oncoproteins that were not identified in this study. Yet, the p53 expression was diffusely aberrant in all polyoma T-antigen-expressing cases, as also in polyoma $\mathrm{T}$ antigen non-expressing cases suggesting alternate mechanisms of p53 sequestration in these tumors.

The long latent period between viral infection and onset of malignancies, presence of infection before oncogenic transformation, lack of viral particles in tumor and immunohistochemical and molecular evidence of virus in the tumor raises the possibility of polyoma virus being oncogenic in a small subset of urologic carcinomas. This study validates the efficacy of the UCSF500 targeted nextgeneration sequencing assay that incorporates viral probes in identifying viral integration in tumors. It further demonstrates aggressive clinicopathologic features of polyoma virus-associated carcinomas with $\mathrm{T}$-antigen and p53 expression, showing clonal viral integration in the human genome with random distribution of breakpoints across the human and viral genome, internal structural rearrangements in the virus, and lack of recurrent hotspots. While the functional significance of the viral integration remains unclear, the clonal nature of viral integration and the differing rates of mutations between $\mathrm{T}$-antigenexpressing and non-expressing carcinomas are intriguing given that $\mathrm{T}$-antigen functions to interrupt several pathways frequently mutated in urothelial carcinoma. Future studies to understand the functional significance of viral integration and disruption of human and viral genome are warranted to fully understand the precise role of BK virus in these neoplasms. As data continues to accumulate to ascertain the mechanistic role of BK virus in post-transplant urologic carcinomas and establish management strategies, the aggressive outcomes seen in these cases suggests that surveillance is warranted to monitor BK viral loads and provide close follow up for patients with high viral loads for development of carcinomas.

Funding Targeted next-generation sequencing was funded by Department of Pathology, University of California, San Francisco.

\section{Compliance with ethical standards}

Conflict of interest The authors declare that they have no conflict of interest.

\section{References}

1. Engels EA, Pfeiffer RM, Fraumeni JF Jr, et al. Spectrum of cancer risk among US solid organ transplant recipients. JAMA. 2011;306:1891-901.

2. Sawinski D, Goral S. BK virus infection: an update on diagnosis and treatment. Nephrol Dial Transplant. 2015;30:209-17.

3. Pinto M, Dobson S. BK and JC virus: a review. J Infect. 2014;68: S2-8.

4. Gardner SD, MacKenzie EF, Smith C, et al. Prospective study of the human polyomaviruses BK and JC and cytomegalovirus in renal transplant recipients. J Clin Pathol. 1984;37:578-86.

5. Geddes CC, Gunson R, Mazonakis E, et al. BK viremia surveillance after kidney transplant: single-center experience during a change from cyclosporine-to lower-dose tacrolimus-based primary immunosuppression regimen. Transpl Infect Dis. 2011;13:109-16.

6. Gaziev J, Paba P, Miano R, et al. Late-onset hemorrhagic cystitis in children after hematopoietic stem cell transplantation for thalassemia and sickle cell anemia: a prospective evaluation of polyoma (BK) virus infection and treatment with cidofovir. Biol Blood Marrow Transplant. 2010;16:662-71.

7. Wong AS, Chan $\mathrm{KH}$, Cheng VC, et al. Relationship of pretransplantation polyoma $\mathrm{BK}$ virus serologic findings and $\mathrm{BK}$ viral reactivation after hematopoietic stem cell transplantation. Clin Infect Dis. 2007;44:830-7.

8. Papadimitriou JC, Randhawa $\mathrm{P}$, Rinaldo $\mathrm{CH}$, et al. BK polyomavirus infection and renourinary tumorigenesis. Am J Transplant. 2016;16:398-406. 
9. Kenan DJ, Mieczkowski PA, Burger-Calderon R, et al. The oncogenic potential of BK-polyomavirus is linked to viral integration into the human genome. J Pathol. 2015;237:379-89.

10. Kenan DJ, Mieczkowski PA, Latulippe E, et al. BK polyomavirus genomic integration and large $\mathrm{T}$ antigen expression: evolving paradigms in human oncogenesis. Am J Transplant. 2017;17:1674-80.

11. Li JY, Fang D, Yong TY, Klebe S, et al. Transitional cell carcinoma in a renal allograft with BK nephropathy. Transpl Infect Dis. 2013;15:E270-2.

12. Alexiev BA, Randhawa P, Vazquez Martul E, et al. BK virusassociated urinary bladder carcinoma in transplant recipients: report of 2 cases, review of the literature, and proposed pathogenetic model. Hum Pathol. 2013;44:908-17.

13. Dufek S, Haitel A, Muller-Sacherer T, et al. Duct Bellini carcinoma in association with BK virus nephropathy after lung transplantation. J Heart Lung Transplant. 2013;32:378-9.

14. Grippo PJ, Sandgren EP. Highly invasive transitional cell carcinoma of the bladder in a simian virus $40 \mathrm{~T}$-antigen transgenic mouse model. Am J Pathol. 2000;157:805-13.

15. Zhou H, Huang HY, Shapiro E, et al. Urothelial tumor initiation requires deregulation of multiple signaling pathways: implications in target-based therapies. Carcinogenesis. 2012;33:770-80.

16. Shah KV, Daniel RW, Warszawski RM. High prevalence of antibodies to BK virus, an SV40-related papovavirus, in residents of Maryland. J Infect Dis. 1973;128:784-7.

17. Vanchiere JA. Human polyomaviruses. In: Feigin RD, editor. Feigin and Cherry's textbook of pediatric infectious diseases. 8th ed. Philadelphia, PA: Elsevier; 2018. pp. 1345-50.

18. Loghavi S, Bose S. Polyomavirus infection and urothelial carcinoma. Diagn Cytopathol. 2011;39:531-5.

19. Kline CN, Joseph NM, Grenert JP, et al. Targeted next-generation sequencing of pediatric neuro-oncology patients improves diagnosis, identifies pathogenic germline mutations, and directs targeted therapy. Neuro Oncol. 2017;19:699-709.

20. Naccache SN, Federman S, Veeraraghavan N, et al. A cloudcompatible bioinformatics pipeline for ultrarapid pathogen identification from next-generation sequencing of clinical samples. Genome Res. 2014;24:1180-92.

21. Sanborn JZ, Salama SR, Grifford M, et al. Double minute chromosomes in glioblastoma multiforme are revealed by precise reconstruction of oncogenic amplicons. Cancer Res. 2013;73:6036-45.

22. Favero F, McGranahan N, Salm M, et al. Glioblastoma adaptation traced through decline of an IDH1 clonal driver and macroevolution of a double-minute chromosome. Ann Oncol. 2015;26:880-7.

23. Li H, Durbin R. Fast and accurate long-read alignment with Burrows-Wheeler transform. Bioinformatics. 2010;26:589-95.

24. Statgen [Internet]. https://github.com/statgen/statgen, accessed April 2017.

25. McKenna A, Hanna M, Banks E, et al. The Genome Analysis Toolkit: a MapReduce framework for analyzing next-generation DNA sequencing data. Genome Res. 2010;20:1297-303.
26. Cancer Stat Facts. Bladder cancer. https://seer.cancer.gov/statfa $\mathrm{cts} / \mathrm{html} /$ urinb.html, accessed May, 2017.

27. Bialasiewicz S, Cho Y, Rockett R, et al. Association of micropapillary urothelial carcinoma of the bladder and BK viruria in kidney transplant recipients. Transpl Infect Dis. 2013;15:283-9.

28. Smith SC, Trpkov K, Chen YB, et al. Tubulocystic carcinoma of the kidney with poorly differentiated foci: a frequent morphologic pattern of fumarate hydratase-deficient renal cell carcinoma. Am J Surg Pathol. 2016;40:1457-72.

29. Seo AN, Yoon G, Ro JY. Clinicopathologic and molecular pathology of collecting duct carcinoma and related renal cell carcinomas. Adv Anat Pathol. 2017;24:65-77.

30. Wenzel K, Felix SB, Flachmeier $\mathrm{C}$, et al. Identification and characterization of KAT, a novel gene preferentially expressed in several human cancer cell lines. Biol Chem. 2003;384:763-75.

31. Hu L, Wang RY, Cai J, et al. Overexpression of CHKA contributes to tumor progression and metastasis and predicts poor prognosis in colorectal carcinoma. Oncotarget. 2016;7:66660-78.

32. Kwee SA, Hernandez B, Chan O, et al. Choline kinase alpha and hexokinase-2 protein expression in hepatocellular carcinoma: association with survival. PLoS ONE. 2012;7:e46591.

33. Stojnev S, Ristic-Petrovic A, Velickovic LJ, et al. Prognostic significance of mucin expression in urothelial bladder cancer. Int $\mathrm{J}$ Clin Exp Pathol. 2014;7:4945-58.

34. Mohseni M, Cidado J, Croessmann S, et al. MACROD2 overexpression mediates estrogen independent growth and tamoxifen resistance in breast cancers. Proc Natl Acad Sci USA. 2014;111:17606-11.

35. Gau DM, Lesnock JL, Hood BL, et al. BRCA1 deficiency in ovarian cancer is associated with alteration in expression of several key regulators of cell motility: a proteomics study. Cell Cycle. 2015;14:1884-92.

36. Tsang WY, Dynlacht BD. Double identity of SCAPER: a substrate and regulator of cyclin A/Cdk2. Cell Cycle. 2008;7:702-5.

37. Kumar VAA, Aster JC. Cellular responses to stress and toxic insults: adaptation, injury, and death. In: Kumar V, Abbas AB, Fausto N, Aster JC, editors. Robbins and Cotran pathologic basis of disease. 9th ed. Philadelphia, PA: Saunders; 2015. pp. 265-340.

38. Dalianis T, Hirsch HH. BK polyomavirus and transformation: cancer associated viruses. New York, NY: Springer; 2012. pp. 419-32.

39. Doolittle-Hall JM, Cunningham Glasspoole DL, et al. Metaanalysis of DNA tumor-viral integration site selection indicates a role for repeats, gene expression and epigenetics. Cancers. 2015;7:2217-35.

40. Martel-Jantin C, Filippone C, Cassar O, et al. Genetic variability and integration of Merkel cell polyomavirus in Merkel cell carcinoma. Virology. 2012;426:134-42.

41. Dyson N, Howley PM, Munger K, et al. The human papilloma virus-16 E7 oncoprotein is able to bind to the retinoblastoma gene product. Science. 1989;243:934-7. 